\title{
Is aerosol formation in cirrus clouds possible?
}

\author{
J. Kazil ${ }^{1,2}$, E. R. Lovejoy ${ }^{1}$, E. J. Jensen ${ }^{3}$, and D. R. Hanson ${ }^{4}$ \\ ${ }^{1}$ NOAA Earth System Research Laboratory, Boulder, CO, USA \\ ${ }^{2}$ NRC Research Associateship Programs, Washington, D.C., USA \\ ${ }^{3}$ NASA Ames Research Center, Moffett Field, CA, USA \\ ${ }^{4}$ Augsburg College, Minneapolis, MN, USA
}

Received: 18 October 2006 - Published in Atmos. Chem. Phys. Discuss.: 28 November 2006

Revised: 19 February 2007 - Accepted: 20 February 2007 - Published: 28 February 2007

\begin{abstract}
The recent observation of ultrafine aerosol particles in cirrus clouds has raised the question whether aerosol formation within cirrus clouds is possible, and if so, what mechanisms are involved. We have developed an aerosol parcel model of neutral and charged $\mathrm{H}_{2} \mathrm{SO}_{4} / \mathrm{H}_{2} \mathrm{O}$ aerosol processes, including nucleation from the gas phase and loss onto cirrus ice particles. Laboratory thermodynamic data for sulfuric acid uptake and loss by small neutral and charged clusters are used, allowing for a reliable description of both neutral and charged nucleation down to the very low temperatures occurring in the upper troposphere and lower stratosphere. The model implements a first order scheme for resolving the aerosol size distribution within its geometric size sections, which efficiently suppresses numerical diffusion. We operate the model offline on trajectories generated with a detailed 1D cirrus model which describes ice crystal nucleation, deposition growth, vertical advection of ice crystals and water vapor, and ice crystal sedimentation. In this paper we explore the possibility of aerosol formation within nonconvective cirrus clouds and draw conclusions for aerosol formation in anvil cirrus. We find that sulfate aerosol formation within cirrus clouds can proceed even at high ice surface area concentrations, and depends strongly on the size of the cirrus ice crystals and on the surface area concentration of preexisting aerosol particles.
\end{abstract}

\section{Introduction}

Aerosol formation from the gas phase requires concentrations of condensable molecules permitting the emergence of supercritical molecular clusters, particles whose growth due to uptake of gas phase molecules is uninhibited by a thermodynamic barrier. This nucleation process is more likely to occur when preexisting aerosol surface area concentrations are low, as preexisting aerosol is a sink for condensable gases and therby suppresses nucleation. Preexisting aerosol also removes freshly nucleated particles by coagulation. The observation of high ultrafine aerosol concentrations in cirrus clouds by Lee et al. (2004) and the possibility that these particles formed within the cloud thus challenge conventional wisdom, as cirrus clouds typically exhibit large surface area concentrations. It has therefore been suggested that the observed ultrafine particles were artifacts of ice crystals shattering in the measurement device (Lee et al., 2004). On the other hand, the upper troposphere exhibits favorable conditions for aerosol formation, including low temperatures, and within cirrus clouds, high relative humidities. Elevated water vapor concentrations within cirrus clouds could result in an enhanced production of the hydroxyl radical and consequently of gas phase sulfuric acid. Other processes potentially promoting aerosol formation in cirrus clouds include yet unidentified heterogeneous processes on ice surfaces producing aerosol precursors, and the homogeneous nucleation of hydrophobic organic molecules (Kulmala et al., 2006).

Whether aerosol formation within cirrus clouds is possible, and if so, what mechanisms are involved is not a purely academic question: Visible cirrus cover $\sim 20-40 \%$ of the globe (Liou, 1986; Wang et al., 1996; Wylie and Menzel, 1999). At the same time the upper troposphere, where cirrus clouds are commonly found, is a potentially important source of new particles supplying the troposphere and stratosphere with condensation nuclei (Brock et al., 1995; Clarke et al., 1998; Eichkorn et al., 2002; Lee et al., 2003; Kazil et al., 2006). A role of cirrus in upper tropospheric aerosol formation could therefore have significant implications for tropospheric and stratospheric processes.

Correspondence to: J. Kazil

(jan.kazil@noaa.gov)

Published by Copernicus GmbH on behalf of the European Geosciences Union. 


\section{Model}

We have developed an aerosol parcel model describing neutral and charged $\mathrm{H}_{2} \mathrm{SO}_{4} / \mathrm{H}_{2} \mathrm{O}$ aerosol, its formation from the gas phase, and its loss onto cirrus ice crystals. The present version of the model utilizes a new treatment of the neutral $\mathrm{H}_{2} \mathrm{SO}_{4} / \mathrm{H}_{2} \mathrm{O}$ cluster thermodynamic data. The hydrated $\mathrm{H}_{2} \mathrm{SO}_{4}$ dimer $\left(\mathrm{H}_{2} \mathrm{SO}_{4}\right)_{2}\left(\mathrm{H}_{2} \mathrm{O}\right)_{x}$ and trimer $\left(\mathrm{H}_{2} \mathrm{SO}_{4}\right)_{3}\left(\mathrm{H}_{2} \mathrm{O}\right)_{y}$ formation thermodynamic data, averaged over the cluster water contents, are calculated explicitly based on fits to the recent laboratory measurements by Hanson and Lovejoy (2006). These fits read, with the humidity over water RHw in $\%$,

$$
\begin{aligned}
& d S\left(\mathrm{kcal} \mathrm{mol}^{-1} \mathrm{~K}^{-1}\right)=-0.04 \\
& d H\left(\mathrm{kcal} \mathrm{mol}^{-1}\right)=-18.32-4.55 \times 10^{-3} \times \mathrm{RHw}
\end{aligned}
$$

for the dimer formation and

$$
\begin{array}{ll}
d S\left(\mathrm{kcal} \mathrm{mol}^{-1} \mathrm{~K}^{-1}\right) & =-0.045 \\
d H\left(\mathrm{kcal} \mathrm{mol}^{-1}\right) & =-21.41-2.63 \times 10^{-2} \times \mathrm{RHw}
\end{array}
$$

for the trimer formation. For the uptake and loss of sulfuric acid and water by small charged clusters the model employs laboratory thermodynamic data measured by Froyd and Lovejoy (2003b). The thermodynamic data for large aerosol particles derive from $\mathrm{H}_{2} \mathrm{SO}_{4}$ and $\mathrm{H}_{2} \mathrm{O}$ vapor pressures over bulk solutions calculated with the Aerosol Inorganics Model (Carslaw et al., 1995), and from the liquid drop model. The thermodynamic data for intermediate size particles are a smooth interpolation of the data from these sources. An exponential form of the correction to the liquid drop model Gibbs free energy for neutral cluster as introduced by Lovejoy et al. (2004) is used. In the present case, the correction has been adjusted to better match the dimer and trimer data in Eqs. (1) and (2): The term $3 e^{-(m+n) / 5} \mathrm{kcal} / \mathrm{mol}$ is added to the liquid drop Gibbs free energies for the addition of a sulfuric acid molecule to a $\left(\mathrm{H}_{2} \mathrm{SO}_{4}\right)_{m-1}\left(\mathrm{H}_{2} \mathrm{O}\right)_{n}$ cluster and for the addition of a water molecule to a $\left(\mathrm{H}_{2} \mathrm{SO}_{4}\right)_{m}\left(\mathrm{H}_{2} \mathrm{O}\right)_{n-1}$ cluster. The present neutral thermodynamic data predict more stable small neutral clusters and more efficient neutral nucleation than the previous treatment (Lovejoy et al., 2004).

The rate coefficients for sulfuric acid uptake and loss by the aerosol particles, for the coagulation of the aerosol particles among themselves, and for the recombination of the negatively charged aerosol with cations are averaged over the equilibrium $\mathrm{H}_{2} \mathrm{O}$ content probability distribution of the aerosol. This simplification holds well in the troposphere, where water is more abundant by orders of magnitude than sulfuric acid, so that the clusters always have enough time to equilibrate with respect to water uptake/loss before colliding with a $\mathrm{H}_{2} \mathrm{SO}_{4}$ molecule. Details of the rate coefficient calculations are given by Lovejoy et al. (2004).

The rate coefficients for loss of sulfuric acid and aerosol particles onto cirrus ice crystals are calculated with the Fuchs formula (Fuchs, 1964; Jacobson, 1999), which gives Brownian diffusion rate coefficients for loss onto particles much larger than the air mean free path. A mass accommodation coefficient of 1 is assumed based on the work of Hanson (2005). In the rate coefficient calculation the cirrus particles are represented by spheres with the surface area and mass of hexagonal column ice crystals with an aspect ratio of 3 .

The model implements a hybrid kinetic-sectional scheme: In the kinetic part, the model resolves the concentrations of the $\left(\mathrm{H}_{2} \mathrm{SO}_{4}\right)_{i}\left(\mathrm{H}_{2} \mathrm{O}\right)_{j(i)}$ and $\mathrm{HSO}_{4}^{-}\left(\mathrm{H}_{2} \mathrm{SO}_{4}\right)_{i-1}\left(\mathrm{H}_{2} \mathrm{O}\right)_{j^{-}(i)}$ clusters individually with $i \leq 21 . j(i)$ and $j^{-}(i)$ are the mean $\mathrm{H}_{2} \mathrm{O}$ contents of the clusters based on the the cluster water content probability distribution in equilibrium. For $i>21$ up to particle diameters of $\sim 1 \mu \mathrm{m}$ the model uses geometric bins. The size distribution within these bins is resolved with linear functions, which suppresses numerical diffusion better than a doubling of the bin number at a negligible computational expense. Along a trajectory, the rate coefficients and mean cluster $\mathrm{H}_{2} \mathrm{O}$ contents are recalculated whenever temperature or relative humidity change by more than $0.5 \mathrm{~K}$ or 2 percentage points, respectively, whichever occurs first. A reduction of these values has no effect on the conclusions of this work. The initial anion in the model is assumed to be $\mathrm{NO}_{3}^{-}\left(\mathrm{HNO}_{3}\right)$, the cation population is represented by $\mathrm{H}_{3} \mathrm{O}^{+}\left(\mathrm{H}_{2} \mathrm{O}\right)_{4}$.

\section{Input data}

We operate the model offline on trajectories in the upper troposphere near $12.5 \mathrm{~km}$, generated with a detailed 1D cirrus model (Jensen and Pfister, 2004) which describes ice crystal nucleation, deposition growth, vertical advection of ice crystals and water vapor, and ice crystal sedimentation. In this work we focus on cirrus clouds that form in either a slow $\left(-10^{-4} \mathrm{~K} \mathrm{~s}^{-1}\right)$ or a fast $\left(-10^{-3} \mathrm{~K} \mathrm{~s}^{-1}\right)$ updraft, resulting in larger but less numerous or smaller but more numerous ice particles, respectively: The largest ice crystal concentration on the slow updraft trajectory is $0.012 \mathrm{~cm}^{-3}$, with a size distribution peak near $60 \mu \mathrm{m}$ particle size, and $0.373 \mathrm{~cm}^{-3}$ on the fast trajectory, with a size distribution peak near $30 \mu \mathrm{m}$ particle size. The average ice surface area concentration is considerably higher in the fast updraft cirrus with $407 \mu \mathrm{m}^{2} \mathrm{~cm}^{-3}$, versus $28 \mu \mathrm{m}^{2} \mathrm{~cm}^{-3}$ in the slow updraft cirrus. These surface area concentrations are calculated assuming that the cirrus ice crystals are hexagonal columns with an aspect ratio of 3 , and the particle sizes are diameters of volume-equivalent spheres.

Figure 1 shows the evolution of pressure, temperature, relative humidity over water and ice, and ice surface area concentration along the two trajectories. The irregular structure of the slow updraft cirrus ice surface area time series (Fig. 1a) is due to sedimentation of the cirrus particles from and across the considered air parcel. A similar but less 

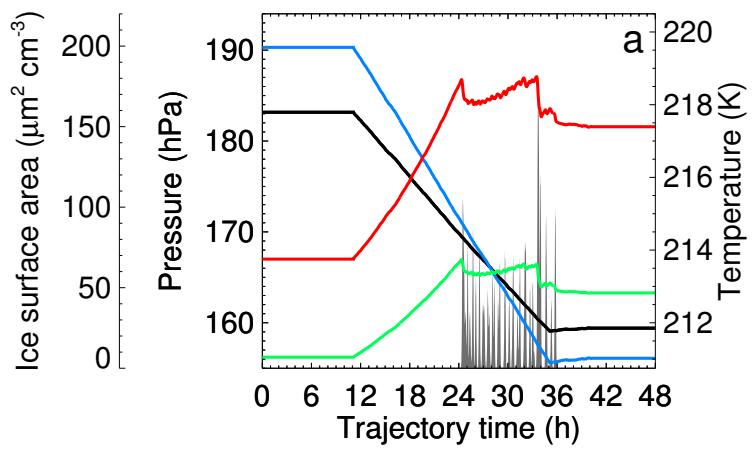

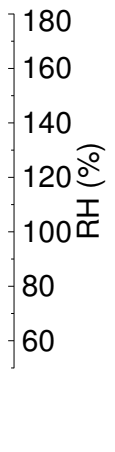

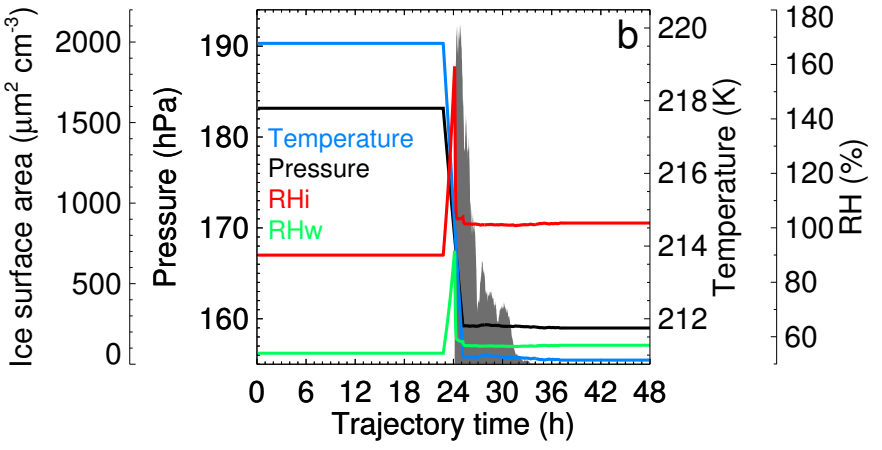

Fig. 1. Ambient conditions and cirrus ice surface area concentrations (gray areas) along the slow (a) and fast (b) updraft trajectories, generated with a 1D cirrus model (Jensen and Pfister, 2004). RHi and RHw denote the relative humidity over a flat ice and a flat water surface, respectively.

prominent variability is seen in the fast updraft cirrus ice surface area time series (Fig. 1b).

The cirrus considered in this work form in the absence of convective activity, and the chemical composition and aerosol properties along the trajectories need to be specified accordingly. However, upper tropospheric chemical composition and aerosol properties exhibit a fair amount of variability due to transport of anthropogenic and volcanic emissions (Thornton et al., 1996), and due to convection, which lifts boundary layer air and initiates aerosol formation aloft, most notably in the tropics (Clarke et al., 1998; Kazil et al., 2006). The specification of a typical upper tropospheric background chemical and aerosol state is therefore not straightforward. Based on their systematic measurements of upper tropospheric aerosol concentrations, Minikin et al. (2003) give an average concentration of Aitken particles (with diameters $>14 \mathrm{~nm}$ ) of $770 \mathrm{~cm}^{-3}$ (at $273 \mathrm{~K}$ and $1000 \mathrm{hPa}$ ) at northern hemisphere mid-latitudes. This corresponds to 175 particles per $\mathrm{cm}^{3}$ in the ambient conditions at the start of our trajectories. We neglect the concentrations of ultrafine aerosol measured by Minikin et al. (2003), who attribute these particles to locally or regionally confined pollution events. Hagen et al. (1995) measured concentrations of aerosol with diameters $>17 \mathrm{~nm}$ in the mid-latitude upper troposphere. They identified two types of aerosol size distributions in and around cirrus clouds: One that can be well described with a single log-normal distribution function, and the other being characterized by elevated concentrations of small particles, possibly originating from a recent nucleation event. We therefore initialize our model with a preexisting log-normal size distribution of neutral aerosol with a geometric mean diameter of $62.5 \mathrm{~nm}$ and a geometric standard deviation of 1.45 , in accord with the high altitude measurements of Hagen et al. (1995). The total particle concentration of this initial size distribution is $175 \mathrm{~cm}^{-3}$, its surface area concentration $2.84 \mu \mathrm{m}^{2} \mathrm{~cm}^{-3}$.
For the calculation of the $\mathrm{H}_{2} \mathrm{SO}_{4}$ production rate, $\mathrm{OH}$ and $\mathrm{SO}_{2}$ concentrations need to be specified. We assume $\mathrm{SO}_{2}$ volume mixing ratios between 10 and 200 ppt, with a median near 40 ppt based on observations in the Pacific upper troposphere north of $20^{\circ}$ (Thornton et al., 1999). Upper tropospheric $\mathrm{OH}$ mixing ratios at northern mid-latitudes range up to $0.4 \mathrm{ppt}$ (Jaeglé et al., 2000). We set the noon $\mathrm{OH}$ mixing ratio to $0.3 \mathrm{ppt}$, corresponding to a concentration of $1.7 \times 10^{6} \mathrm{~cm}^{-3}$, and parameterize the $\mathrm{OH}$ diurnal cycle as a half sine centered around noon, with a day length of $12 \mathrm{~h}$, while setting nighttime $\mathrm{OH}$ concentrations to zero. The production rate of sulfuric acid is then calculated under the assumption that the reaction $\mathrm{SO}_{2}+\mathrm{OH}$ is the rate-limiting step of the oxidation chain $\mathrm{SO}_{2} \rightarrow \mathrm{H}_{2} \mathrm{SO}_{4}$ (Lovejoy et al., 1996). We use solar maximum galactic cosmic ray ionization rates calculated with the code of O'Brien (2005) for $210^{\circ} \mathrm{E}, 35^{\circ} \mathrm{N}$ and for the ambient conditions along the trajectories.

\section{Results}

\subsection{Daytime cirrus}

Figure 2 shows gas phase $\mathrm{H}_{2} \mathrm{SO}_{4}$ and aerosol concentrations calculated with our aerosol parcel model on the slow (Fig. 1a) and on the fast (Fig. 1b) updraft trajectory for different $\mathrm{SO}_{2}$ volume mixing ratios. The cirrus formation has been synchronized with sunrise in order to examine the effect of cirrus particles on in-cloud aerosol formation.

Within the slow updraft cirrus (Fig. 2a), gas phase $\mathrm{H}_{2} \mathrm{SO}_{4}$ concentrations rise to levels permitting aerosol nucleation at $\mathrm{SO}_{2}$ mixing ratios as low as $15 \mathrm{ppt}$, yielding several hundred supercritical particles per $\mathrm{cm}^{3}$. At $45 \mathrm{ppt} \mathrm{SO}_{2}$, many thousand supercritical particles form per $\mathrm{cm}^{3}$ in the cloud, but only negligible concentrations of particles larger than $3 \mathrm{~nm}$ in diameter. These larger particles appear at $60 \mathrm{ppt} \mathrm{SO}_{2}$, and attain appreciable concentrations of several thousand per $\mathrm{cm}^{3}$ within the cloud at $90 \mathrm{ppt} \mathrm{SO}_{2}$. 

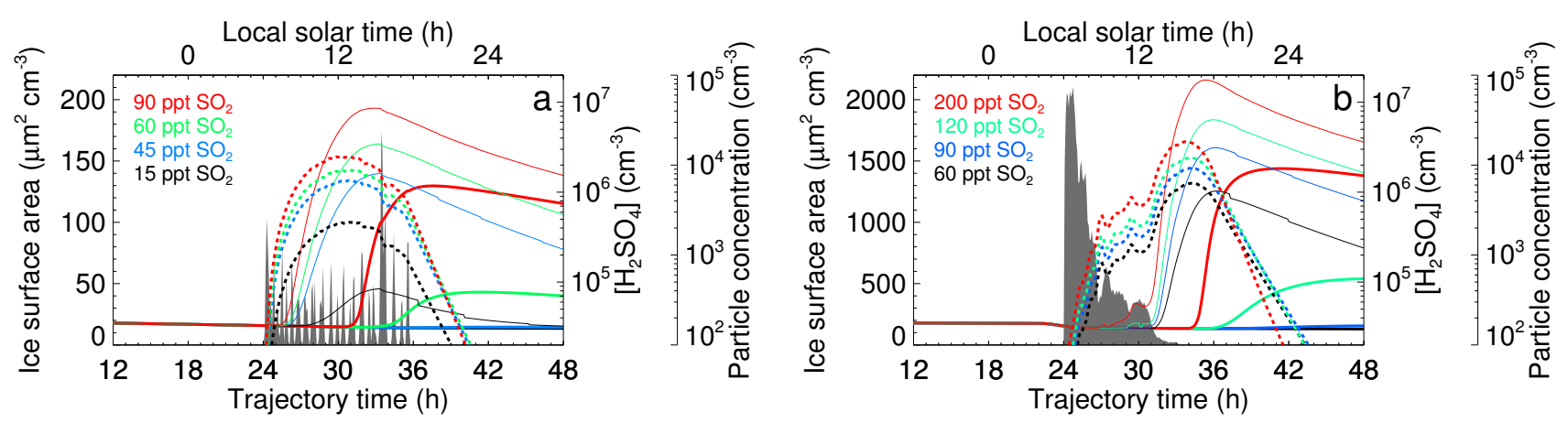

Fig. 2. Daytime slow (a) and fast (b) updraft cirrus; the cirrus ice surface area concentration is denoted by gray areas. Broken lines represent the $\mathrm{H}_{2} \mathrm{SO}_{4}$ concentration, thin solid lines the concentration of supercritical aerosol particles, thick solid lines the concentration of aerosol particles with diameters $>3 \mathrm{~nm}$.

In the fast updraft cirrus the large surface area concentrations remove sulfuric acid quickly from the gas phase (Fig. 2b). This rapid removal manifests most prominently as dents in the $\mathrm{H}_{2} \mathrm{SO}_{4}$ concentration that are collocated with peaks in the surface area time series. Nucleation is strongly inhibited and supercritical aerosol concentrations remain low even at high $\mathrm{SO}_{2}$ mixing ratios until sedimentation of the ice crystals has depleted the cloud. The dissipation of the cloud prompts an increase in $\mathrm{H}_{2} \mathrm{SO}_{4}$ concentration and aerosol nucleation, followed by the formation of larger ( $>3 \mathrm{~nm}$ diameter) particles.

\subsection{Nighttime cirrus}

Figure 3 shows gas phase $\mathrm{H}_{2} \mathrm{SO}_{4}$ and aerosol concentrations on the slow (Fig. 1a) and fast (Fig. 1b) updraft trajectories which have been shifted with respect to the diurnal cycle so that the cirrus clouds form at sunset, illustrating the effect of ice surface area on aerosol that formed prior to the cloud.

Aerosol particles exceeding $3 \mathrm{~nm}$ in diameter that formed in the course of the day endure the slow updraft cirrus cloud nearly unscathed (Fig. 3a), their slow decline is mainly due to coagulation among themselves. Particle concentrations are reduced more distinctly in the fast updraft cirrus (Fig. 3b), but a fair portion of the $3 \mathrm{~nm}$ particles survives the cloud phase. The fast updraft cirrus almost instantly removes all sulfuric acid from the gas phase, while the removal is more gradual in the slow updraft case.

A closer inspection of Fig. 3 reveals that the concentration of particles larger than $3 \mathrm{~nm}$ is slightly higher at the time of the cirrus formation on the fast updraft trajectory (Fig. 3b) compared with the slow updraft trajectory (Fig. 3a): While the $\mathrm{SO}_{2}$ mixing ratios are held constant along the trajectories, the $\mathrm{SO}_{2}$ concentrations decrease due to the expansion of the air parcel in the updraft, which starts at $11 \mathrm{~h}$ (trajectory time) on the slow updraft trajectory (Fig. 1a), but at $22.5 \mathrm{~h}$ (trajectory time) on the fast updraft trajectory. As a consequence the $\mathrm{SO}_{2}$ concentration is lower during daytime on the slow updraft trajectory, resulting in lower $\mathrm{H}_{2} \mathrm{SO}_{4}$ production rates.

\section{Discussion}

The removal of condensable gases from the gas phase is diffusion limited for particles that are much larger than the mean free path length of air, which is typically $<1 \mu \mathrm{m}$ in the troposphere. Hence cirrus ice crystals remove $\mathrm{H}_{2} \mathrm{SO}_{4}$ molecules from the gas phase less efficiently per unit surface area than smaller aerosol particles.

This is illustrated in Fig. 4, which shows the effect of variations in preexisting aerosol surface area concentration on aerosol formation in the case of the slow updraft cirrus, with a $\mathrm{SO}_{2}$ volume mixing ratio of 90 ppt. Three initial neutral aerosol populations are compared, with surface area concentrations of $1.42,2.84$, and $5.68 \mu \mathrm{m}^{2} \mathrm{~cm}^{-3}$, corresponding to $\mathrm{H}_{2} \mathrm{SO}_{4}$ condensational sinks of $7.5 \times 10^{-5}, 1.5 \times 10^{-4}$, and $3 \times 10^{-4} \mathrm{~s}^{-1}$, respectively. A geometric mean diameter of $62.5 \mathrm{~nm}$ and a geometric standard deviation of 1.45 is assumed in all three cases. The $\mathrm{H}_{2} \mathrm{SO}_{4}$ condensational sinks were calculated with

$s=\int_{2}^{n_{\max }} d n k(n) \rho(n)$

where $s$ is the condensational sink (Kulmala et al., 2001), $\rho(n)$ the concentration of aerosol particles containing between $n$ and $n+d n \mathrm{H}_{2} \mathrm{SO}_{4}$ molecules, and $k(n)$ the rate coefficient for the uptake of $\mathrm{H}_{2} \mathrm{SO}_{4}$ by a neutral particle containing $n \mathrm{H}_{2} \mathrm{SO}_{4}$ molecules, calculated with the Fuchs formula (Fuchs, 1964; Jacobson, 1999). $n_{\max } \approx 2 \times 10^{9}$ is the $\mathrm{H}_{2} \mathrm{SO}_{4}$ content of the largest aerosol particles taken into account in our model simulations.

An increase of the preexisting aerosol surface area concentration from 2.84 to $5.68 \mu \mathrm{m}^{2} \mathrm{~cm}^{-3}$ completely halts the formation of $>3 \mathrm{~nm}$ diameter particles, while a decrease to $1.42 \mu \mathrm{m}^{2} \mathrm{~cm}^{-3}$ markedly boosts the concentrations of these 

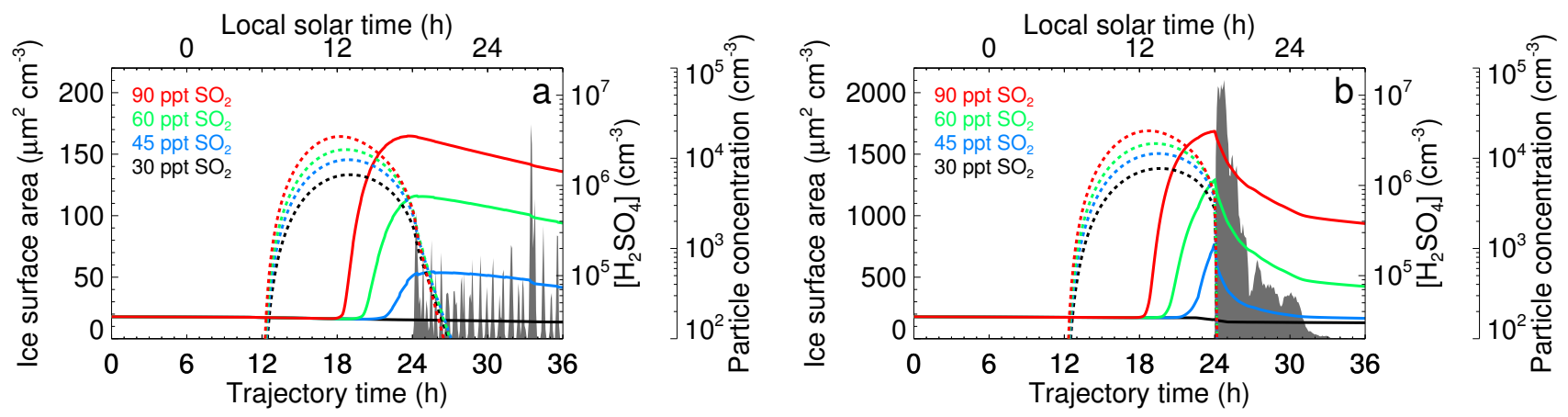

Fig. 3. Nighttime slow (a) and fast (b) updraft cirrus; the cirrus ice surface area concentration is denoted by gray areas. Broken lines represent the $\mathrm{H}_{2} \mathrm{SO}_{4}$ concentration, thick solid lines the concentration of particles with diameters $>3 \mathrm{~nm}$.

particles (Fig. 4). This strong dependence of particle formation on preexisting aerosol surface area concentration is due to the comparably low average $\mathrm{H}_{2} \mathrm{SO}_{4}$ condensational sink of $5.3 \times 10^{-5} \mathrm{~s}^{-1}$ of the cirrus cloud, despite its higher average surface area concentration of $28 \mu \mathrm{m}^{2} \mathrm{~cm}^{-3}$. The diffusion limited removal of sulfuric acid from the gas phase by cirrus ice, together with the low temperatures in the upper troposphere explains why aerosol formation can proceed in cirrus clouds.

Our study does not directly address anvil cirrus clouds with very large ice surface area concentrations, in which Lee et al. (2004) observed high numbers of ultrafine particles: Anvil cirrus form in a highly dynamic environment associated with convection, and cannot be easily compared with the cirrus in our simulations. Nonetheless, we can explore the conditions under which aerosol formation proceeds in the presence of very large ice surface area concentrations:

Figure 5 shows results for two idealized cirrus clouds consisting of $19 \mu \mathrm{m}$ or $78 \mu \mathrm{m}$ ice crystals, with a surface area concentration of $1250 \mu \mathrm{m}^{2} \mathrm{~cm}^{-3}$ in both cases, and a zero preexisting aerosol surface area concentration. For $1 \mathrm{ppb}$ $\mathrm{SO}_{2}$, the cloud with the smaller crystals completely suppresses the formation of $>3 \mathrm{~nm}$ diameter aerosol, while a massive nucleation event occurs in the cloud with the larger crystals, leading to the formation of $>3 \mathrm{~nm}$ diameter particles at concentrations in the thousands per $\mathrm{cm}^{3}$. The striking difference is due to the slower removal of sulfuric acid from the gas phase in the cloud with the larger ice crystals: The $\mathrm{H}_{2} \mathrm{SO}_{4}$ condensational sink is $2.2 \times 10^{-4} \mathrm{~s}^{-1}$ in the case of the larger, and $8.7 \times 10^{-4} \mathrm{~s}^{-1}$ in the case of the smaller ice crystals.

While not common, $\mathrm{SO}_{2}$ mixing ratios in the ppb range have been observed in the upper troposphere (Arnold et al., 1997). A process that could establish such high $\mathrm{SO}_{2}$ levels is the convective lifting of polluted boundary layer air which may contain $\mathrm{SO}_{2}$ at mixing ratios of many ppb (e.g. Hanke et al., 2003). This is a plausible scenario as anvil cirrus form due to strong convective updrafts, which are capable of lifting boundary layer air as high as into the stratosphere, even at mid-latitudes (Fischer et al., 2003). Boundary layer air may also contain aerosol precursor gases other than $\mathrm{SO}_{2}$. These precursor gases need not necessarily nucleate, but could contribute to the condensational growth of freshly nucleated sulfuric acid/water particles.

In the cases considered in our simulations, ionization rates amount to values around $30 \mathrm{~cm}^{-3} \mathrm{~s}^{-1}$, but neutral nucleation dominates over charged nucleation by at least a factor of two. The charged nucleation rate may be underestimated in our model for different reasons: The cation population is represented by a proton hydrate in our model. However, positive sulfuric acid/water clusters, while less potent to promote aerosol nucleation compared with their negative counterparts at temperatures of the lower troposphere (Froyd and Lovejoy, 2003a), might grow to stable sizes in upper tropospheric conditions and thus contribute to aerosol formation. Stable neutral aerosol particles can also form from the recombination of subcritical positive and negative sulfuric acid/water clusters or other complex cations and anions.

\section{Conclusions}

The formation of sulfate aerosol from the gas phase in cirrus clouds is possible, and facilitated by the relatively inefficient, diffusion limited removal of sulfuric acid from the gas phase by cirrus ice crystals, and by the low temperatures in the upper troposphere. Neutral nucleation dominates over charged nucleation in the considered cases. In nonconvective cirrus that form in slow updrafts and thus exhibit comparably low surface area concentrations, aerosol nucleation is possible at $\mathrm{SO}_{2}$ mixing ratios as low as 15 ppt. Formation of larger ( $>3 \mathrm{~nm}$ diameter) aerosol particles within these clouds requires $\mathrm{SO}_{2}$ mixing ratios elevated within the range of values found in the northern mid-latitude upper troposphere. In cirrus with large ice surface area concentrations, such as formed by fast updrafts or due to convective activity, aerosol nucleation and growth are strongly inhibited, and require very high $\mathrm{SO}_{2}$ levels to proceed. In the case of anvil 


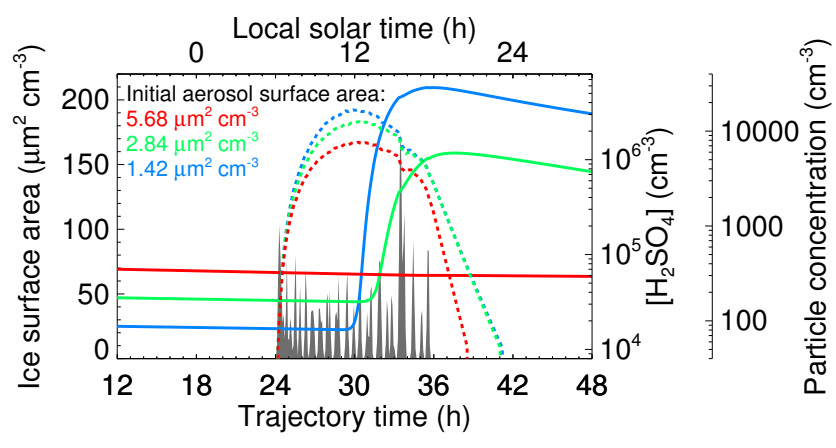

Fig. 4. Effect of preexisting aerosol surface area concentration on $>3 \mathrm{~nm}$ aerosol particle formation in the slow updraft cirrus. Cirrus ice surface area concentration is denoted by gray areas. Broken lines represent the $\mathrm{H}_{2} \mathrm{SO}_{4}$ concentration, thick solid lines the concentration of particles with diameters $>3 \mathrm{~nm}$.

cirrus, such high $\mathrm{SO}_{2}$ concentrations could be established by transport of polluted boundary layer air into the upper troposphere, along with other aerosol precursor gases by the convective updraft that is responsible for the formation of the cirrus cloud. Aerosol particles that nucleate and grow to larger sizes before the formation of a cirrus cloud can persist in considerable numbers within the cloud, even at high ice surface area concentrations.

The concentrations of aerosol precursor gases required for aerosol nucleation within cirrus depend not only on the cirrus ice surface area concentration, but strongly on the surface area concentration of preexisting aerosol, and on the size of the cirrus ice crystals. Comparably moderate variations in preexisting aerosol surface area or ice crystal sizes can make the difference between an absent and a vigorous aerosol nucleation event.

Our simulations do not account for positive sulfuric acid/water clusters, other complex cations and anions, aerosol precursor molecules other than $\mathrm{H}_{2} \mathrm{SO}_{4}$ and $\mathrm{H}_{2} \mathrm{O}$, or for processes such as heterogeneous chemistry on ice surfaces. While not a prerequisite, they could promote aerosol formation and growth within cirrus clouds with very high ice surface area concentrations, or when $\mathrm{SO}_{2}$ and $\mathrm{OH}$ concentrations alone would not suffice.

Acknowledgements. We would like to thank D. M. Murphy, R. Talukdar, and R. Sommariva (NOAA Earth System Research Laboratory) for helpful discussions, and two anonymous referees for their thoughtful review of our manuscript. This research was performed while the first author held a National Research Council Research Associateship Award, and supported by the NOAA Climate and Global Change Program.

Edited by: T. Koop

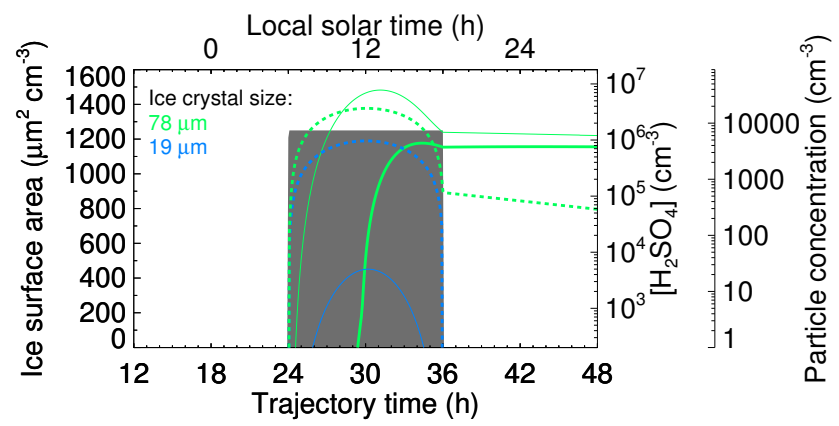

Fig. 5. Aerosol formation in two idealized cirrus clouds with an ice surface area concentration of $1250 \mu \mathrm{m}^{2} \mathrm{~cm}^{-3}$ (gray area), at constant conditions of $170 \mathrm{hPa}, 210 \mathrm{~K}$, and $150 \%$ relative humidity over ice. The first cloud consists of $19 \mu \mathrm{m}$, the second of $78 \mu \mathrm{m}$ ice crystals. The day length is $12 \mathrm{~h}$, the noon $\mathrm{OH}$ volume mixing ratio $0.3 \mathrm{ppt}$, and the $\mathrm{SO}_{2}$ volume mixing ratio $1 \mathrm{ppb}$ in both cases. Preexisting aerosol surface area concentration has been set to zero. Broken lines represent the $\mathrm{H}_{2} \mathrm{SO}_{4}$ concentration, thin solid lines the concentration of supercritical aerosol particles, thick solid lines the concentration of aerosol particles with diameters $>3 \mathrm{~nm}$. Nucleation is negligible in the presence of the smaller, but vigorous in the presence of the larger ice crystals. In the latter case, $>3 \mathrm{~nm}$ diameter aerosol particles are produced in vast numbers.

\section{References}

Arnold, F., Schneider, J., Gollinger, K., Schlager, H., Schulte, P., Hagen, D. E., Whitefield, P. D., and Velthoven, P. v.: Observation of upper tropospheric sulfur dioxide- and acetone-pollution: Potential implications for hydroxyl radical and aerosol formation, Geophys. Res. Lett., 24(1), 57-60, doi:10.1029/96GL03693, 1997.

Brock, C. A., Hamill, P., Wilson, J. C., Jonsson, H. H., and Chan, K. R.: Particle formation in the upper tropical troposphere: a source of nuclei for the stratospheric aerosol, Science, 270, 1650-1653, 1995.

Carslaw, K. S., Clegg, S. L., and Brimblecombe, P.: A thermodynamic model of the system $\mathrm{HCl}-\mathrm{HNO}_{3}-\mathrm{H} 2 \mathrm{SO}_{4}-\mathrm{H}_{2} \mathrm{O}$, including solubilities of $\mathrm{HBr}$, from $<200 \mathrm{~K}$ to $328 \mathrm{~K}$, J. Phys. Chem., 99, 11 557-11 574, 1995.

Clarke, A. D., Varner, J. L., Eisele, F., Mauldin, R. L., Tanner, D., and Litchy, M.: Particle production in the remote marine tropospere: Cloud outflow and subsidence during ACE 1, J. Geophys. Res., 103, 16397-16409, 1998.

Eichkorn, S., Wilhelm, S., Aufmhoff, H., Wohlfrom, K. H., and Arnold, F.: Cosmic ray-induced aerosol-formation: First observational evidence from aircraft-based ion mass spectrometer measurements in the upper troposphere, Geophys. Res. Lett., 29(14), doi:10.1029/2002GL015044, 2002.

Fischer, H., de Reus, M., Traub, M., Williams, J., Lelieveld, J., de Gouw, J., Warneke, C., Schlager, H., Minikin, A., Scheele, R., and Siegmund, P.: Deep convective injection of boundary layer air into the lowermost stratosphere at midlatitudes, Atmos. Chem. Phys., 3, 739-745, 2003, http://www.atmos-chem-phys.net/3/739/2003/.

Froyd, K. D. and Lovejoy, E. R.: Experimental Thermodynamics of 
Cluster Ions Composed of $\mathrm{H}_{2} \mathrm{SO}_{4}$ and $\mathrm{H}_{2} \mathrm{O}$. 1. Positive Ions, J. Phys. Chem. A, 107, 9800-9811, 2003a.

Froyd, K. D. and Lovejoy, E. R.: Experimental Thermodynamics of Cluster Ions Composed of $\mathrm{H}_{2} \mathrm{SO}_{4}$ and $\mathrm{H}_{2} \mathrm{O}$. 2. Measurements and ab Initio Structures of Negative Ions, J. Phys. Chem. A, 107, 9812-9824, 2003b.

Fuchs, N. A.: The Mechanics of Aerosols, Macmillan, 1964.

Hagen, D. E., Podzimek, J., and Trueblood, M. B.: Uppertropospheric aerosol sampled during project FIRE IFO II., J. Atmos. Sci., 52, 4196-4209, 1995.

Hanke, M., Umann, B., Uecker, J., Arnold, F., and Bunz, H.: Atmospheric measurements of gas-phase $\mathrm{HNO}_{3}$ and $\mathrm{SO}_{2}$ using chemical ionization mass spectrometry during the MINATROC field campaign 2000 on Monte Cimone, Atmos. Chem. Phys., 3, 417436, 2003 , http://www.atmos-chem-phys.net/3/417/2003/

Hanson, D. R.: Mass accommodation of $\mathrm{H}_{2} \mathrm{SO}_{4}$ and $\mathrm{CH}_{3} \mathrm{SO}_{3} \mathrm{H}$ on water-sulfuric acid solutions from $6 \%$ to $97 \%$ RH, J. Phys. Chem. A, 109, 6919-6927, doi:10.1021/jp0510443, 2005.

Hanson, D. R. and Lovejoy, E. R.: Measurement of the thermodynamics of the hydrated dimer and trimer of sulfuric acid, J. Phys. Chem. A, 110, 9525-9528, doi:10.1021/jp062844w, 2006.

Jacobson, M. Z.: Fundamentals of atmospheric modeling, Cambridge University Press, 1999.

Jaeglé, L., Jacob, D. J., Brune, W. H., Faloona, I., Tan, D., Heikes, B. G., Kondo, Y., Sachse, G. W., Anderson, B., Gregory, G. L., Singh, H. B., Pueschel, R., Ferry, G., Blake, D. R., and Shetter, R. E.: Photochemistry of $\mathrm{HO}_{\mathrm{x}}$ in the upper troposphere at northern midlatitudes, J. Geophys. Res., 105, 3877-3892, doi: 10.1029/1999JD901016, 2000.

Jensen, E. and Pfister, L.: Transport and freeze-drying in the tropical tropopause layer, J. Geophys. Res., 109, D02207, doi: 10.1029/2003JD004022, 2004.

Kazil, J., Lovejoy, E. R., Barth, M. C., and O’Brien, K.: Aerosol nucleation over oceans and the role of galactic cosmic rays, Atmos. Chem. Phys., 6, 4905-4924, 2006, http://www.atmos-chem-phys.net/6/4905/2006/.

Kulmala, M., Dal Maso, M., Mäkelä, J. M., Pirjola, L., Väkevä, M., Aalto, P., Miikkulainen, P., Hämeri, K., and O'Dowd, C. D.: On the formation, growth and composition of nucleation mode particles, Tellus B, 53, 479-490, doi:10.1034/j.1600-0889.2001. 530411.x, 2001.

Kulmala, M., Reissell, A., Sipilä, M., Bonn, B., Ruuskanen, T. M., Lehtinen, K. E. J., Kerminen, V.-M., and Ström, J.: Deep convective clouds as aerosol production engines: Role of insoluble organics, J. Geophys. Res., 111, 17202 , doi:10.1029/ 2005JD006963, 2006.
Lee, S.-H., Reeves, J. M., Wilson, J. C., Hunton, D. E., Viggiano, A. A., Miller, T. M., Ballenthin, J. O., and Lait, L. R.: Particle Formation by Ion Nucleation in the Upper Troposphere and Lower Stratosphere, Science, 301, 1886-1889, 2003.

Lee, S.-H., Wilson, J. C., Baumgardner, D., Herman, R. L., Weinstock, E. M., LaFleur, B. G., Kok, G., Anderson, B., Lawson, P., Baker, B., Strawa, A., Pittman, J. V., Reeves, J. M., and Bui, T. P.: New particle formation observed in the tropical/subtropical cirrus clouds, J. Geophys. Res., 109, 20 209, doi: 10.1029/2004JD005033, 2004.

Liou, K.-N.: Influence of Cirrus Clouds on Weather and Climate Processes: A Global Perspective, Mon. Wea. Rev., 114, 11671199, doi:10.1175/1520-0493, 1986.

Lovejoy, E. R., Hanson, D. R., and Huey, L. G.: Kinetics and products of the gas-phase reaction of $\mathrm{SO}_{3}$ with water, J. Phys. Chem., 100, 19911-19916, doi:10.1021/jp962414d, 1996.

Lovejoy, E. R., Curtius, J., and Froyd, K. D.: Atmospheric ioninduced nucleation of sulfuric acid and water, J. Geophys. Res., 109, D08204, doi:10.1029/2003JD004460, 2004.

Minikin, A., Petzold, A., Ström, J., Krejci, R., Seifert, M., van Velthoven, P., Schlager, H., and Schumann, U.: Aircraft observations of the upper tropospheric fine particle aerosol in the Northern and Southern Hemispheres at midlatitudes, Geophys. Res. Lett., 30, 1503, doi:10.1029/2002GL016458, 2003.

O'Brien, K.: The theory of cosmic-ray and high-energy solarparticle transport in the atmosphere, in: The natural radiation environment VII, edited by: McLaughlin, J. P., Simopoulos, E. S., and Steinhäusler, F., Elsevier, seventh International Symposium on the Natural Radiation Environment, Rhodes, Greece, 20-24 May 2002, 2005.

Thornton, D. C., Bandy, A. R., Blomquist, B. W., Davis, D. D., and Talbot, R. W.: Sulfur dioxide as a source of condensation nucle in the upper troposphere of the Pacific Ocean, J. Geophys. Res., 101, 1883-1890, 1996.

Thornton, D. C., Bandy, A. R., Blomquist, B. W., Driedger, A. R., and Wade, T. P.: Sulfur dioxide distribution over the Pacific Ocean 1991-1996, J. Geophys. Res., 104, 5845-5854, 1999.

Wang, P.-H., Minnis, P., McCormick, M. P., Kent, G. S., and Skeens, K. M.: A 6-year climatology of cloud occurrence frequency from Stratospheric Aerosol and Gas Experiment II observations (1985-1990), J. Geophys. Res., 101, 29 407-29430, doi:10.1029/96JD01780, 1996.

Wylie, D. P. and Menzel, W. P.: Eight Years of High Cloud Statistics Using HIRS., J. Clim., 12, 170-184, 1999. 